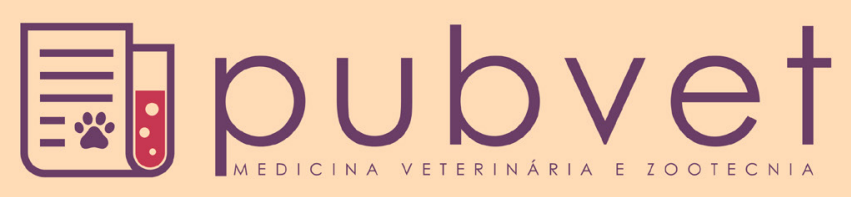

HTTP://DX.DOI.ORG/10.22256/PUBVET.VIIN5.482-488

\title{
Digestibilidade, proteína digestível e energia metabolizável do grão e farelo de girassol para galos de crescimento lento
}

\author{
Raimunda Thyciana Vasconcelos Fernandes ${ }^{1 *}$, Alex Martins Varela de Arruda ${ }^{2}$, Aurora \\ da Silva Melo ${ }^{1}$, Jéssica Berly Moreira Marinho ${ }^{3}$
}

${ }^{I}$ Zootecnistas, Doutorandas em Ciência Animal da Universidade Federal Rural do Semi-Arid.o. ${ }^{2}$ Zootecnista, Docente do Departamento de Ciências Animais, Universidade Federal Rural do Semi-Árido. ${ }^{3}$ Zootecnista

*Autor para correspondencia, E-mail: fernandesrtv@hotmail.com

RESUMO. Este trabalho foi realizado com o objetivo de determinar o valor nutricional, a digestibilidade aparente dos nutrientes, a proteína digestível aparente e a metabolização da energia do farelo e do grão do girassol para galos de crescimento lento. Foram utilizados 15 galos Label Rouge com 40 semanas de idade, distribuídos em delineamento inteiramente casualizado, com três tratamentos: ração referência (RR), e com inclusão de $20 \%(\mathrm{~kg} / \mathrm{kg})$ do grão (GG) ou farelo de girassol (FG). As aves foram alojadas individualmente em gaiolas metálicas adaptadas para coleta total de excretas. Os coeficientes de digestibilidade aparente dos subprodutos, grão e farelo de girassol foram: 67,09 e 75,88\% para matéria seca, 24,56 e 28,55\% para proteína bruta, 10,14 e 17,28\% para proteína digestível aparente, 94,17 e $77,37 \%$ para extrato etéreo, 4,27 e 6,61\% para fibra em detergente neutro, 3,30 e 6,64\% para fibra em detergente ácido, 63,83 e 57,67\% para coeficiente de metabolização da energia bruta, 3.945 e $2.840 \mathrm{kcal} / \mathrm{kg}$ para energia metabolizável aparente e disponibilidade de 2,58 e $12,22 \%$ para matéria mineral. A inclusão de $20 \%$ de grão e farelo de girassol em rações para galos de crescimento lento propiciou redução da digestibilidade aparente de todos os nutrientes, exceto para extrato etéreo, coeficiente de metabolização da energia bruta e energia metabolizável aparente onde o grão de girassol mostrou-se superior.

Palavras chave: fatores antinutricionais, fibra, Helianthus annuus

\section{Digestibility, protein digestible and metabolizable energy of grain and sunflower meal for growth slow roosters}

ABSTRACT. This study was realized to determine the nutritional value, digestibility of nutrients, apparent digestible protein and metabolizable energy of grain and sunflower meal to slow growth roosters. 15 roosters of Label Rouge were distributed in a completely randomized design with three treatments: reference ration (RR), from which were included $20 \%(\mathrm{~kg} / \mathrm{kg})$ of grain $(\mathrm{SG})$ and sunflower meal $(\mathrm{SM})$. The poultry were housed individually in cages adapted for excreta collection. The apparent digestibility coefficients of byproducts, grain and sunflower meal were: 67.09 and $75.88 \%$ for dry matter, 24.56 and $28.55 \%$ for crude protein, 10.14 and $17.28 \%$ for apparent digestible protein, 94.17 and $77.37 \%$ for ether extract, 4.27 and $6.61 \%$ for neutral detergent fiber, 3.30 and $6.64 \%$ for acid detergent fiber, 63.83 and $57.67 \%$ for metabolisation coefficient of gross energy, 3945 and $2840 \mathrm{kcal} / \mathrm{kg}$ for apparent metabolisable energy and availability of 2.58 and $12.22 \%$ for mineral matter. The inclusion of $20 \%$ of grain and sunflower meal in diets for slow growth roosters caused a reduction of the apparent digestibility of all nutrients except for ether extract, metabolisation coefficient of gross energy and metabolisable energy, where the grain sunflower showed if higher.

Keywords: antinutritional factors, fiber, Helianthus annuus 


\title{
Digestibilidad, proteína digestible y energía metabolizable de grano y salvado de girasol para gallos de crecimiento lento
}

\begin{abstract}
RESUMEN. El objetivo de este estudio fue determinar el valor nutricional, la digestibilidad de nutrientes, la proteína digestible aparente y la energía metabolizable del grano y el salvado de girasol a los gallos de crecimiento lento. Se distribuyeron 15 gallos de la línea Label Rouge en un diseño completamente al azar con tres tratamientos distribuidos en: ración de referencia (RR), con inclusión de $20 \%(\mathrm{~kg} / \mathrm{kg})$ de grano (GG) y salvado de girasol (SG). Las aves fueron alojadas individualmente en jaulas adaptadas para la colecta total de excretas. Los coeficientes de digestibilidad aparente de subproductos, grano y salvado de girasol fueron: 67,09 y $75,88 \%$ para la materia seca, 24,56 y $28,55 \%$ para la proteína cruda, 10,14 y $17,28 \%$ para la proteína digestible aparente, 94,17 y $77,37 \%$ 63,83 y $57,67 \%$ para el coeficiente de metabolización de la energía bruta, 3945 y $2840 \mathrm{kcal}$ / kg para la energía aparentemente metabolizable y la disponibilidad de 2,58 y 12,22\% para la materia mineral. La inclusión del $20 \%$ de salvado y grano de girasol en dietas para gallos de crecimiento lento causó una reducción de la digestibilidad aparente de todos los nutrientes, excepto el extracto etéreo, el coeficiente de metabolización de la energía bruta y la energía metabolizable.
\end{abstract}

Palabras Clave: factores antinutricionales, fibra, Helianthus annuus

\section{Introdução}

Responsável por 70 a $80 \%$ da composição da ração de aves, os grãos como milho e soja têm trazido preocupação para os produtores de aves, devido a alta do preço destes grãos no mercado brasileiro e a diminuição dos estoques públicos nas regiões consumidoras, impulsionando assim as cadeias produtivas a procurar medidas emergenciais para abastecer o mercado com preços acessíveis e, reduzir prejuízos. Essa alta associada à desvalorização do real frente ao dólar, que amplia as exportações de milho e soja, pressiona os custos de produção de aves, já que estes grãos podem impactar significativamente o total dos custos. Diante deste cenário, os produtores buscam alternativas para reduzir os custos de produção, como a substituição parcial destes grãos nas rações (Marques and Piracicaba, 2016).

Nesse contexto, o aumento do cultivo do girassol, destinado à indústria alimentícia ou refinarias de biocombustível, disponibiliza em diversas regiões brasileiras grandes quantidades de subprodutos nas formas de grãos, tortas e farelos. Estes subprodutos são caracterizados por apresentar elevados teores de proteína bruta (entre 28 e 44\%), e de energia bruta (entre 4229 e 6218 $\mathrm{kcal} \mathrm{kg}$ ), dependendo da forma de processamento utilizada para extração do óleo e da quantidade de fibra presente, e podem ser utilizadas na formulação de dietas, destacando-se os frangos de corte, frangas de reposição e galinhas poedeiras
(Araújo et al., 2014, Fernandes et al., 2013, , Fernandes et al., 2015).

Devido à relevância do desenvolvimento de pesquisas que avaliem alimentos alternativos que viabilizem cada vez mais a produção avícola, objetivou-se determinar a digestibilidade aparente dos nutrientes, a proteína digestível e a metabolização da energia do grão e farelo de girassol em dietas para galos de crescimento lento.

\section{Material e Métodos}

O experimento foi aprovado pela Comissão de Ética no Uso de Animais da Universidade Federal Rural do Semi-Árido (CEUA - UFERSA, parecer $\mathrm{N}^{\circ} 65 / 2012$, processo $\mathrm{N}^{\circ} 23091.001795 / 2012-49$ ) e conduzido no Setor de Avicultura do Departamento de Ciências Animais da mesma Instituição. A temperatura média durante o período experimental foi de $29,6^{\circ} \mathrm{C}$, e a média da umidade relativa foi de $65,0 \pm 5^{\circ} \mathrm{C}$.

Os alimentos avaliados foram: o grão do girassol, que passou por processo de moagem com diâmetro geométrico médio $(\mathrm{DGM})=1030 \mu \mathrm{m}$ e o farelo do girassol, sendo assim denominado devido a sua granulometria $(\mathrm{DGM}=1030 \mu \mathrm{m})$, porém foi obtido através da prensagem mecânica em mini usina de biodiesel no Estado do Rio Grande Norte, sendo comumente chamado de torta de girassol. Os alimentos foram submetidos às análises de matéria seca (MS), proteína bruta (PB), extrato etéreo (EE), fibra detergente ácido (FDA), fibra detergente neutro (FDN) e matéria mineral (MM) seguindo a metodologia descrita 
por (Silva and Queiroz, 2002). A energia bruta (EB) foi determinada através de bomba calorimétrica adiabática IKA WERK modelo 2000.

Foram selecionados 15 galos da linhagem de crescimento lento Label Rouge, com 40 semanas de idade, baseados no peso corporal médio, e alojados individualmente em gaiolas de digestibilidade metálicas com dimensões de $40 \mathrm{x}$ $40 \times 22 \mathrm{~cm}$, dispostas em sistemas de baterias, providas de bebedouro semiautomático do tipo nipple, comedouro tipo calha e bandejas adaptadas à contenção e coletas das excretas.

O período experimental foi de 14 dias ( 7 dias de adaptação +7 dias de coleta de excretas). Durante todo o período (adaptação e coleta), as dietas e as sobras foram pesadas (250 g/ave/dia) e a água foi fornecida à vontade. A coleta total de excretas foi realizada seguindo recomendações descritas por Sakomura and Rostagno (2007), duas vezes ao dia (8h00min e 16h00min), sendo as amostras acondicionadas em sacos plásticos, identificadas e congeladas ($\left.10^{\circ} \mathrm{C}\right)$.

As aves foram distribuídas em um delineamento inteiramente casualizado com três tratamentos, que consistiram em três rações experimentais, sendo uma referência (RR) formuladas a partir de ingredientes convencionais (milho, farelo de soja e farelo de trigo), e as demais contendo a substituição dos macro ingredientes em nível de $20 \%(\mathrm{~kg} / \mathrm{kg})$ por grão (GG) e farelo de girassol (FG), (Tabela 1). A dieta controle foi elaborada considerando a composição dos alimentos e as exigências nutricionais recomendadas por Rostagno et al. (2011) para linhagens semipesadas.

Ao término do período de coleta de excretas, as amostras foram descongeladas a temperatura ambiente, homogeneizadas e destinadas às análises químicas, seguindo as técnicas descritas por Silva and Queiroz (2002). Após estas análises, foram determinados os coeficientes de digestibilidade dos nutrientes e de metabolizabilidade da energia, conforme técnica convencional de Materson para avaliação de alimentos como descrita por Sakomura and Rostagno (2007).

\footnotetext{
$C D A=$ ((Nutriente consumido - Nutriente fecal)/Nutriente consumido) x100)

EMA = ((Energia Bruta ingerida - Energia Bruta excretada)/Matéria seca ingerida)
}

$C M E B=(($ Energia MetabolizáveV Energia Bruta $) x$ 100)

$E M A S=E M A_{R C O}+\left(\left(E M A_{S U B}-E M A_{R}\right) / C S T / C R T\right)$

Onde*:

$\mathrm{CDA}=$ Coeficiente de digestibilidade aparente

$\mathrm{EMA}=$ Energia metabolizável aparente

CMEB = Coeficiente de metabolização da energia (\%)

EMAS $=$ Energia metabolizável do subproduto-teste $(\mathrm{kcal} / \mathrm{kg})$

$\mathrm{EMA}_{\mathrm{R}}=$ Energia metabolizável aparente da ração referência $(\mathrm{kcal} / \mathrm{kg})$;

$\mathrm{EMA}_{\mathrm{SUB}}=$ Energia metabolizável aparente da ração teste $(\mathrm{kcal} / \mathrm{kg})$;

CST $=$ Consumo do subproduto-teste $(\mathrm{kg})$;

CRT $=$ Consumo da ração com o subproduto-teste $(\mathrm{kg})$

* Equações válidas para todos os nutrientes

Tabela 1. Fórmula percentual em ingredientes e composição nutricional da ração referência

\begin{tabular}{ll}
\hline Ingredientes & $\mathrm{kg}$ \\
\hline Farelo de soja & 29,60 \\
Milho moído & 59,30 \\
Farelo de trigo & 5,00 \\
Calcário calcítico $^{\text {Fosfato bicálcico }}$ & 0,95 \\
Óleo de soja $^{\text {Sal marinho }}$ & 1,20 \\
Premix mineral $^{1}$ & 2,20 \\
Premix vitamínico $^{1}$ & 0,45 \\
Salinomicina & 0,48 \\
L-lisina Hcl $^{\text {DL-metionina }}$ & 0,45 \\
Total & 0,03 \\
\hline
\end{tabular}

Composição nutricional, \%

Matéria seca (MS) 88,17

Matéria mineral (MM) $\quad 6,06$

Extrato etéreo (EE) 4,82

Fibra detergente neutro (FDN) $\quad 12,97$

Fibra detergente ácido (FDA) $\quad 4,90$

$\begin{array}{ll}\text { Fibra Bruta }(\mathrm{FB})^{2} & 3,07\end{array}$

Proteína bruta (PB) $\quad 19,74$

Energia bruta (EB) $k c a l / k g \quad 4.073$

Lisina total $^{2} \quad 0,98$

Lisina digestível $^{2} \quad 0,88$

Metionina total $^{2} \quad 0,28$

Metionina digestível $^{2} \quad 0,25$

Cálcio $^{2} \quad 0,75$

Fósforo total ${ }^{2} \quad 0,58$

Fósforo disponível $^{2} \quad 0,12$

Mistura vitamínica ${ }^{1}$ (kg do produto) $=$ : vit. A:10.000.000UI.; vit. D3: 2.000.000UI.; vit. E: $30.000 U$.; vit. B1: 2,0 g; vit. B2: 6,0 g; vit. B6: 4,0 g; vit. B12: $0,015 \mathrm{~g}$; ác. pantotênico: $12,0 \mathrm{~g}$; biotina: $0,1 \mathrm{~g}$; vit. K3: $3,0 \mathrm{~g}$; ác. fólico: $1,0 \mathrm{~g}$; ác. nicotínico: $50,0 \mathrm{~g}$; Se:250,0 mg; Mistura mineral ( $\mathrm{kg}$ do produto $)=$ Fe: $80 \mathrm{~g}$; Cu: 10g; Co: 2g; Mn: 80g; Zn: 50g; I: $1 \mathrm{~g}$.; ${ }^{2}$ Valores estimados de acordo com (Rostagno et al., 2011). 
Os dados obtidos foram submetidos à análise de homocedasticidade e normalidade dos erros, após foram removidos os dados discrepantes identificados (outliers e influentes) e em seguida submetidos à análise de variância, e as médias foram comparadas pelo teste Tukey em nível de $5 \%$ de probabilidade através do software estatístico R Development Core Team (2011).

\section{Resultados e Discussão}

Os dados de composição nutricional do farelo de girassol avaliado (Tabela 2) diferem dos valores encontrados por Rostagno et al. (2011), onde os valores foram inferiores para MS $(89,74 \%)$, EE (1,78\%), FDN (41,01\%) e EB $(4,289 \mathrm{kcal} / \mathrm{kg})$ e superiores para PB $(30,22 \%)$, FDA $(24,89 \%)$ e MM ( $5,98 \%)$.

Contudo, os valores de PB, MM e EB do farelo de girassol são muito próximos dos referenciados por Tavernari et al. (2010) 28,09\%, 5,67\% e 4.429 $\mathrm{kcal} / \mathrm{kg}$ e Mantovani et al. (2008) de 92,68\% e $4229 \mathrm{kcal} / \mathrm{kg}$ para MS e EB, respectivamente. Enquanto a composição nutricional do grão de girassol aproxima-se da reportada por Mantovani et al. (2008) de $93,10 \%, 21,75 \%$ e $6.218 \mathrm{kcal} / \mathrm{kg}$, para MS, PB e EB, respectivamente.

Tabela 2. Composição nutricional do farelo e grão de girassol

\begin{tabular}{lcc}
\hline Constituintes & Farelo & Grão \\
\hline Matéria Seca, \% & 93,11 & 93,91 \\
Proteína Bruta, \% & 28,85 & 24,56 \\
Extrato Etéreo, \% & 13,41 & 46,47 \\
Fibra Detergente Neutro, \% & 33,27 & 19,20 \\
Fibra Detergente Ácido, \% & 23,09 & 12,17 \\
Matéria Mineral, \% & 4,81 & 3,90 \\
Energia Bruta, kcal/kg & 4.924 & 6.180 \\
\hline
\end{tabular}

Os valores médios de consumos das rações diferiram significativamente $(\mathrm{P}<0,05)($ Tabela 3$)$, sendo o maior valor para ração com farelo de girassol (FG) e menor para ração referência (RR). De acordo com Bertechini (2012) e Arruda and Fernandes (2014) tais resultados podem ser atribuídos ao fato de que a fração fibrosa presente na ração com farelo de girassol, resulta em maior motilidade intestinal e como consequência, maior velocidade de passagem do bolo alimentar pelo intestino delgado, e este esvaziamento, proporciona maior consumo desta ração.

Foram observados maiores valores para digestibilidade da MS, FDN, FDA, PB e disponibilidade da MM da RR quando comparada às demais rações experimentais. De acordo com dados disponíveis na literatura, a presença de fitatos no grão e farelo de girassol pode ser responsável pela menor disponibilidade da $\mathrm{MM}$ nas rações GG e FG, exercendo também influência negativa na solubilidade das proteínas, prejudicando a função das pepsinas devido às ligações iônicas entre os grupos fosfato do ácido fítico e aminoácidos como lisina, histidina e arginina (Lima et al., 2013, Fernandes et al., $\underline{2015)}$.

Tabela 3. Consumo das rações referência (RR), com grão (GG) e farelo de girassol (FG) por galos de crescimento lento.

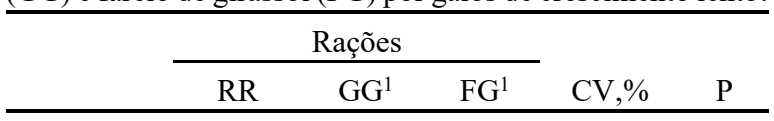

Consumo

\begin{tabular}{llllll} 
(g/ave/dia) & 151,60 & $173,94^{\mathrm{a}}$ & $161,74^{\mathrm{b}}$ & 2,05 & 0,0018 \\
\hline
\end{tabular} a, b: Médias seguidas de mesma letra não diferem pelo teste Tukey $(\mathrm{P}>0,05)$. CV - Coeficiente de Variação; P- Probabilidade.

Os coeficientes de digestibilidade aparente $(\mathrm{CDA})$ dos nutrientes diferiram $(\mathrm{P}<0,05)$ entre as rações (Tabela 4).

Tabela 4. Coeficientes de digestibilidade aparente (CDA) das rações referência (RR), com grão (GG) e farelo de girassol (FG) para galos de crescimento lento.

\begin{tabular}{lccccc}
\hline & \multicolumn{3}{c}{ Rações } & & \\
\cline { 2 - 5 } CDA & RR & GG & FG & CV, \% & P \\
\hline MS, \% & $86,78^{\mathrm{a}}$ & $76,84^{\mathrm{b}}$ & $84,60^{\mathrm{b}}$ & 1,72 & 0,0034 \\
$\mathrm{~PB}, \%$ & $21,51^{\mathrm{a}}$ & $19,74^{\mathrm{c}}$ & $20,65^{\mathrm{b}}$ & 8,22 & 0,0156 \\
$\mathrm{MM}, \%$ & $21,42^{\mathrm{a}}$ & $10,44^{\mathrm{C}}$ & $17,76^{\mathrm{b}}$ & 2,49 & 0,0002 \\
$\mathrm{EE}, \%$ & $91,50^{\mathrm{b}}$ & $94,83^{\mathrm{a}}$ & $88,67^{\mathrm{c}}$ & 1,84 & 0,0007 \\
$\mathrm{FDN}, \%$ & $32,77^{\mathrm{a}}$ & $19,41^{\mathrm{b}}$ & $18,82^{\mathrm{b}}$ & 4,62 & 0,0001 \\
FDA, \% & $27,62^{\mathrm{a}}$ & $17,68^{\mathrm{c}}$ & $21,27^{\mathrm{b}}$ & 14,28 & 0,0235 \\
CMEB, \% & $72,45^{\mathrm{a}}$ & $67,43^{\mathrm{b}}$ & $67,95^{\mathrm{b}}$ & 1,58 & 0,0001 \\
Ema, kcal/kg & $2.951^{\mathrm{b}}$ & $3.160^{\mathrm{a}}$ & $2.928^{\mathrm{b}}$ & 1,54 & 0,0001 \\
\hline ab: Médias seguidas de mesma letra não diferem pelo teste Tukey \\
(P>0,05); CV - Coeficiente de Variação; P- Probabilidade. CMEB
\end{tabular}

A menor digestibilidade da PB observada nas rações GG e FG pode ser atribuída também ao ácido clorogênico, existente principalmente na semente do girassol, que quando sofre oxidação pela polifenoloxidase resulta em substâncias que reagem com a proteína alterando a sua disponibilidade, reduzindo a quantidade de aminoácidos essenciais, especialmente lisina e metionina, a qualidade nutricional, e a digestibilidade da proteína (Pedrosa et al., 2000, González-Pérez et al., 2002, Sen and Bhattacharyya, 2000). Em relação à digestibilidade da fração fibrosa (FDN, FDA), Arruda et al. (2010) levando em consideração que as aves não são monogástricos de ceco funcional, e que a atividade fermentativa microbiana não é 
tão eficiente para degradação da fração fibrosa, e a geração de ácidos graxos voláteis, metabolização da energia e outros produtos benéficos gerados pela biomassa microbiana, pode ser bastante limitada ao hospedeiro pelo grau de complexidade dos polissacarídeos fibrosos, justificando o menor CDA para as rações GG e FG quando comparadas à RR.

Por sua vez, a digestibilidade do EE foi superior para as rações GG e RR, respectivamente, o que pode ser explicado devido ao alto teor de ácidos graxos poli-insaturados na semente (Pinheiro et al., 2002); enquanto o menor valor para FG pode ser explicado pelo processo de extração do óleo por prensagem mecânica, o qual é submetido o girassol e que resulta no farelo rico em fibra, capaz de influenciar a viscosidade da digesta, atividade enzimática e a capacidade de absorção intestinal desses nutrientes (Tavernari et al., 2008, Arruda and Fernandes, 2014).

Quanto ao coeficiente de metabolização da energia bruta (CMEB) das rações, observou-se superioridade para a $R R \quad(p<0,05)$ quando comparada às rações $\mathrm{GG}$ e $\mathrm{FG}$, que por sua vez não diferiram $(\mathrm{p}>0,05)$. Para energia metabolizável aparente (EMA) observou-se superioridade da $\mathrm{GG}(\mathrm{p}<0,05)$ quando comparadas às rações $\mathrm{FG}$ e $\mathrm{RCO}$, que não diferiram entre si $(\mathrm{p}>0,05)$. Tal resultado pode ser explicado pelo fato de que o maior valor de EB encontrado na ração GG, foi suficiente para compensar o menor CMEB quando comparado às demais rações.

Os coeficientes de digestibilidade aparente (CDA) dos nutrientes e de metabolização da energia bruta (CMEB), bem como a proteína digestível aparente (PDA) e energia metabolizável aparente (EMA) dos subprodutos avaliados diferiram $(\mathrm{P}<0,05)$ entre si ( Tabela 5).

Observou-se superioridade do farelo de girassol para os CDA da matéria seca (MS), proteína bruta $(\mathrm{PB})$, proteína digestível aparente (PDA), fração fibrosa (FDN, FDA) e matéria mineral (MM), quando comparado à semente $(\mathrm{P}<0,05)$. A mesma tendência foi observada entre as rações experimentais, contendo $20 \%$ do grão e do farelo de girassol.

Contudo, foi observada superioridade do grão de girassol para o CDA do extrato etéreo (EE), CMEB e EMA, quando comparada ao farelo $(\mathrm{P}<0,05)$. Segundo Tavernari et al. (2010), a presença de fibra solúvel no farelo de girassol pode aumentar a viscosidade intestinal, dificultando a digestão e a absorção dos nutrientes, principalmente dos lipídios, o que resulta em menor aproveitamento da energia.

Tabela 5. Coeficientes de digestibilidade aparente (CDA) dos subprodutos do girassol para galos de crescimento lento

\begin{tabular}{|c|c|c|c|c|}
\hline \multirow[b]{2}{*}{ CDA } & \multicolumn{2}{|c|}{ Subprodutos } & \multirow[b]{2}{*}{ CV $(\%)$} & \multirow[b]{2}{*}{$\mathrm{P}$} \\
\hline & $\begin{array}{l}\text { Grão de } \\
\text { girassol }\end{array}$ & $\begin{array}{c}\text { Farelo de } \\
\text { girassol }\end{array}$ & & \\
\hline MS, \% & $67,09^{\mathrm{b}}$ & $75,88^{a}$ & 2,78 & 0,0001 \\
\hline $\mathrm{PB}, \%$ & $24,56^{\mathrm{b}}$ & $28,85^{\mathrm{a}}$ & 8,91 & 0,0004 \\
\hline PDA, \% & $10,14^{\mathrm{b}}$ & $17,28^{\mathrm{a}}$ & 8,88 & 0,0001 \\
\hline MM, \% & $2,58^{\mathrm{b}}$ & $12,22^{\mathrm{a}}$ & 10,64 & 0,0013 \\
\hline EE, \% & $94,17^{\mathrm{a}}$ & $77,37^{\mathrm{b}}$ & 1,84 & 0,0001 \\
\hline FDN, \% & $4,27^{\mathrm{b}}$ & $6,61^{\mathrm{a}}$ & 15,71 & 0,0217 \\
\hline FDA, $\%$ & $3,30^{\mathrm{b}}$ & $6,64^{\mathrm{a}}$ & 14,28 & 0,0002 \\
\hline CMEB, \% & $63,83^{\mathrm{a}}$ & $57,67^{\mathrm{b}}$ & 11,15 & 0,0001 \\
\hline Ema, $\mathrm{kcal} / \mathrm{kg}$ & $3.945^{\mathrm{a}}$ & $2.840^{\mathrm{b}}$ & 10,28 & 0,0001 \\
\hline
\end{tabular}

ab: Médias seguidas de mesma letra não diferem pelo teste Tukey $(\mathrm{P}>0,05) ; \mathrm{CV}$ - Coeficiente de Variação; P- Probabilidade

O CDA da PB, e a PDA do farelo de girassol aqui apresentados diferiram dos reportados por Rostagno et al. (2011), $85,0 \%$ e $25,7 \%$, respectivamente, o que pode ser atribuído às peculiaridades referentes às condições experimentais, tais como: composição nutricional do subproduto, linhagem utilizada e idade das aves, as quais as pesquisas foram submetidas.

Mantovani et al. (2008) e Tavernari et al. (2010) ao incluírem $20 \%$ deste subproduto em uma ração referência, encontraram para EMA, 1.569 e $2.141 \mathrm{kcal} / \mathrm{kg}$, enquanto Stringhini et al. (2006), ao adicionarem $40 \%$ do alimento em uma ração referência, encontraram para EMA 1.777 $\mathrm{kcal} / \mathrm{kg}$. Dessa maneira, a idade das aves, alimento, composição química, nível de inclusão do alimento, fatores antinutricionais, entre outros, podem influenciar os valores de energia metabolizável (Arruda and Fernandes, 2014).

$\mathrm{O}$ maior valor de EMA para grão quando comparado ao farelo de girassol pode ser justificado pelo maior teor da fração fibrosa (FDA e FDN) presente no farelo. Este resultado também foi observado por Mantovani et al. (2008) que observaram valores para EMA de 4.925 e 1.569 $\mathrm{kcal} / \mathrm{kg}$, para grão e farelo de girassol, respectivamente.

\section{Conclusão}

A inclusão de $20 \%$ de grão e farelo de girassol em rações para galos de crescimento lento propiciou redução da digestibilidade aparente de todos os nutrientes, exceto para extrato etéreo, coeficiente de metabolização da energia bruta e 
energia metabolizável aparente onde o grão de girassol mostrou-se superior.

\section{Referências Bibliográficas}

Araújo, W. A. G., Albino, L. F. T., Rostagno, H. S., Hannas, M. I., Pessoa, G. B. S., Messias, R. K. G., Lelis, G. R. \& Ribeiro Júnior, V. 2014. Sunflower meal and enzyme supplementation of the diet of 21-to 42-d-old broilers. Revista Brasileira de Ciência Avícola, 16, 17-24.

Arruda, A. M. V. \& Fernandes, R. T. V. 2014. Energetic value of forages from semi-arid region and digestibility of rations for naked neck pullets. Revista Caatinga, 27, 232-238.

Arruda, A. M. V., Fernandes, R. T. V., Oliveira, J. F., Filgueira, T. M. B., Fernandes, D. R. \& Galvão, R. J. D. 2010. Valor energético de fenos de forrageiras do semi-árido para aves Isa Label. Acta Veterinaria Brasilica, 4, 105112.

Bertechini, A. G. 2012. Nutrição de monogástricos, 2 ed. Universidade Federal de Lavras, Lavras.

Fernandes, R. T. V., Arruda, A. M. V., Araújo, M. S., Silva Melo, A., Marinho, J. B. M., Oliveira Costa, M. K., Lima, H. F. F., Morais Oliveira, V. R. \& Holanda, J. S. 2015. Valor nutricional e digestibilidade do grão de girassol em dietas para frangas e galos Label Rouge. Acta Veterinaria Brasilica, 9, 12-18.

Fernandes, R. T. V., Arruda, A. M. V., Silva, L. N. S., V. R. M. \& Vasconcelos, N. V. B. 2013. Grão de girassol e seus subprodutos: potenciais fontes proteicas para alimentação de aves. Revista Verde de Agroecologia e Desenvolvimento Sustentável, 8, 40-46.

González-Pérez, S., Merck, K. B., Vereijken, J. M., van Koningsveld, G. A., Gruppen, H. \& Voragen, A. G. J. 2002. Isolation and characterization of undenatured chlorogenic acid free sunflower (Helianthus annuus) proteins. Journal of Agricultural and Food Chemistry, 50, 1713-1719.

Lima, H. F., Fernandes, R. T. V., Costa, M. K. O., Silva, S. L. G., Marinho, J. B. M., Vasconcelos, N. V. B. \& Arruda, A. M. V. 2013. Farelo de girassol na alimentação de aves Label Rouge em crescimento no ambiente equatorial. Acta Veterinaria Brasilica, 7, 56-60.

Mantovani, C., Furlan, A. C., Murakami, A. E., Moreira, I., Scapinello, C. \& da Rosa Santolin,
M. L. 2008. Composição química e valor energético do farelo e da semente de girassol para frangos de corte. Acta Scientiarum. Animal Sciences, 22, 745-749.

Marques, H. L. \& Piracicaba, R. A. 2016. Apesar de preços recordes, setor produtivo de ovos sofre com pressão de custos. Avicultura Industrial, 107, 28-32.

Pedrosa, M. M., Muzquiz, M., García-Vallejo, C., Burbano, C., Cuadrado, C., Ayet, G. \& Robredo, L. M. 2000. Determination of caffeic and chlorogenic acids and their derivatives in different sunflower seeds. Journal of the Science of Food and Agriculture, 80, 459-464.

Pinheiro, J. W., Fonseca, N. A. N., Silva, C. A., Cabrera, L., Bruneli, F. A. T. \& Takahashi, S. E. 2002. Farelo de girassol na alimentação de frangos de corte em diferentes fases de desenvolvimento. Revista Brasileira de Zootecnia, 31, 1418-1425.

R Development Core Team (2011). R: A language and environment for statistical computing. $\mathrm{R}$ Foundation for Statistical Computing, Vienna, Austria. ISBN 3-900051-07-0, URL http://www.R-project.org/.

Rostagno, H. S., Albino, L. F. T., Donzele, J. L., Gomes, P. C., Oliveira, R., Lopes, D. C., Ferreira, A. S., Barreto, S. \& Euclides, R. F. 2011. Composição de alimentos e exigências nutricionais, 3 edn. Universidade Federal de Viçosa, Viçosa.

Sakomura, N. K. \& Rostagno, H. S. 2007. Métodos de pesquisa em nutrição de monogástricos. FUNEP, Jaboticabal.

Sen, M. \& Bhattacharyya, D. K. 2000. Nutritional quality of sunflower seed protein fraction extracted with isopropanol. Plant Foods for Human Nutrition, 55, 265-278.

Silva, D. J. \& Queiroz, A. C. 2002. Análise de alimentos: métodos químicos e biológicos, 3 edn. Universdiade Federal de Viçosa, Viçosa, Minas Gerais, Brasil.

Stringhini, J. H., Café, M. B., Fernandes, C. M., Andrade, M. L., Rocha, P. T. \& Leandro, N. S. M. 2006. Avaliação do valor nutrritivo do farelo de girassol para aves. Ciência Animal Brasileira, 1, 123-126.

Tavernari, F. C., Albino, L. F. T., Dutra, W. M., Júnior, G. R. L., Nery, L. R. \& Maia, R. C. 2008. Farelo de girassol: composição e 
utilização da aimentação de frango de corte. Revista Eletrônica Nutritime, 5, 638-647.

Tavernari, F. C., Ribeiro Júnior, V., Morata, R. L., Albino, L. F. T., Dutra Júnior, W. M. \& Rostagno, H. S. 2010. Avaliação nutricional e energética do farelo de girassol para aves. Arquivo Brasileiro de Medicina Veterinaria e Zootecnia, 62, 172-177.

\section{Article History:}

Received 19 December 2016

Accepted 23 January 2017

Available on line 30 April 2017

License information: This is an open-access article distributed under the terms of the Creative Commons Attribution License 4.0, which permits unrestricted use, distribution, and reproduction in any medium, provided the original work is properly cited. 